\title{
LRP6 as a biomarker of poor prognosis of breast cancer
}

\author{
Yunke Zhang ${ }^{1 \#}$, Chengchang Shu ${ }^{1 \#}$, Yusufu Maimaiti ${ }^{1,2}$, Shuntao Wang ${ }^{1}$, Chong Lu $^{1}$, Jing Zhou ${ }^{1,3}$ \\ ${ }^{1}$ Department of Breast and Thyroid Surgery, Union Hospital, Tongji Medical College, Huazhong University of Science and Technology, Wuhan, \\ China; ${ }^{2}$ Department of General Surgery, People's Hospital of Xinjiang Uygur Autonomous Region, Urumqi, China; ${ }^{3}$ Department of General \\ Surgery, People's Hospital of Dongxihu District, Wuhan, China \\ Contributions: (I) Conception and design: Y Zhang, C Shu, Y Maimaiti, S Wang; (II) Administrative support: C Lu, J Zhou; (III) Provision of study \\ materials or patients: SW, C Lu, J Zhou; (IV) Collection and assembly of data: C Shu, Y Maimaiti; (V) Data analysis and interpretation: C Shu, Y \\ Maimaiti; (VI) Manuscript writing: All authors; (VII) Final approval of manuscript: All authors. \\ \#These authors contributed equally to this work. \\ Correspondence to: Chong Lu; Jing Zhou. Department of Breast and Thyroid Surgery, Union Hospital, Tongii Medical College, Huazhong University \\ of Science and Technology, Wuhan, China. Email: lcwhxh@hust.edu.cn; jzhou_whuh@foxmail.com.
}

Background Recently, low-density lipoprotein receptor (LDLR)-related protein 6 (LRP6) has been the focus of molecular targeted therapy for breast cancer; however, its role in breast cancer is still controversial. The purpose of this study was to investigate the effect of LRP6 overexpression on the prognosis of breast cancer.

Methods: We used immunohistochemistry to detect the expression of LRP6 via tissue microarrays in breast cancer samples, Chi-square test analyze the relationship between LRP6 expression and clinicopathological features of breast cancer, the Kaplan-Meier method to perform survival analysis, and the Cox proportional hazards regression model to explore the potential risk factors of breast cancer. The role of LRP6 in the proliferation, invasion, and metastasis of breast cancer was studied by colony formation, Transwell migration and invasion assay and scratch assay. The tumor-bearing model of LRP6 knockdown was established using MCF-7 cells, and corresponding negative control was set up to observe the growth rate of the two models.

Results: High expression of LRP6 was observed in 89 out of 150 (59.3\%) breast cancer cases, as detected by microarray of breast cancer tissue. Chi-square tests showed no significant correlation between LRP6 expression and tumor size, lymph node staging, or mitosis. Survival analysis showed that the overall survival rate of tumor patients with high LRP6 expression was significantly lower than that of patients with low LRP6 expression. Univariate and multivariate regression analyses revealed that LRP6 was an independent risk factor for breast cancer and was negatively correlated with the prognosis of breast cancer. Compared with the control group, small interference RNA (si-RNA) knockdown of LRP6 significantly reduced the clonogenic rate as well as the migration and invasion abilities of MCF-7 cells. In the scratch experiment, the wound healing ability of the LRP6 knockdown was significantly weaker than that of the control group. There were significant differences in tumor growth weight and volume between lentivirus transfected LRP6 knockdown MCF-7 cell line and control MCF-7 cell line in nude mice.

Conclusions: LRP6 could be a useful biomarker of poor prognosis of breast cancer, as it plays an important role in tumor growth, migration, and invasion.

Keywords: Low-density lipoprotein receptor-related protein 6 (low-density LRP6); breast cancer; prognosis; biomarker

Submitted Mar 27, 2021. Accepted for publication Jul 12, 2021.

doi: $10.21037 / g s-21-194$

View this article at: https://dx.doi.org/10.21037/gs-21-194 


\section{Introduction}

Breast cancer is the most common malignancy among women, and it is also the leading cause of cancer-related deaths in women. In 2019, approximately 268,600 cases of invasive breast cancer and 48,100 cases of ductal carcinoma in situ were diagnosed in the United States, and the number of deaths from these types of cancer reached 41,760 (1). Breast cancer has become the main cause of the high mortality of cancer patients because of its high ability of invasion and metastasis. The treatment strategies for breast cancer include local therapy, chemotherapy, targeted therapy, and endocrine therapy. These treatment strategies depend on many factors such as receptor status, tumor type, tumor size, and metastasis. Problems such as triple negative breast cancer, advanced breast cancer, and drug resistance restrict the application of these treatment strategies.

Members of the low-density lipoprotein receptor (LDLR) family include lipoprotein receptor-related protein (LRP)1, LRP5, LRP6, and LRP8. Cancer cells require higher levels of cholesterol than normal cells for their metabolic needs; thus, cancer cells increase their intracellular cholesterol content by enhancing LDLR receptor-mediated endocytosis of serum LDL (2). LDLR has also been reported to have a cancer-promoting effect, facilitating cancer progression through tumor cell migration $(3,4)$. Several studies have shown that the inhibition of LRP1 expression can lead to morphological changes in tumor cells, thus affecting the interaction between cells and cell matrix, specifically by inhibiting focal adhesion kinase (FAK) activation and preventing tumor cell migration $(5,6)$.

The human LRP6 gene is located on chromosome 12p13.2. The full-length $150 \mathrm{~kb}$ sequence and its 23 exons are highly conserved in all species. The transmembrane protein LRP6, which acts as a coreceptor, transmits signals through the plasma membrane and activates the $\mathrm{Wnt} / \beta$-catenin signal pathway (7). The $\mathrm{Wnt} / \beta$-catenin signaling pathway controls the proliferation, survival, and differentiation of epithelial stem/progenitor cells. Therefore, abnormal activation of this pathway is often observed in cancers of epithelial origin. As an indispensable coreceptor of Wnt, LRP6 is often overexpressed in colorectal cancer, liver cancer and breast cancer, leading to enhancement of the $\mathrm{Wnt} / \beta$-catenin signaling pathway. In addition, LRP6 hyperphosphorylation has been shown to be increased in KRAS mutant cells and patient-derived colorectal tumors (8).

Based on the results of previous studies, in this study, we hypothesized that the high expression of LRP6 has an adverse effect on the prognosis of breast cancer, by promoting tumor cell invasion and metastasis. In this study, we measured the expression levels of LRP6 in a breast cancer tissue chip, studied the effects of LRP6 on the migration and invasion of the breast cancer cell line MCF7 , and carried out experiments of tumorigenesis in nude mice. These experiments were performed to explore the possibility that LRP6 expression levels in early diagnosis could be markers of poor prognosis of breast cancer. Moreover, this research could provide a theoretical basis for the therapeutic application of LRP6 inhibitors in breast cancer, with inhibition of tumor invasion and metastasis.

We present the following article in accordance with the ARRIVE reporting checklist (available at https://dx.doi. org/10.21037/gs-21-194).

\section{Methods}

\section{Sample and tissue chip and immunobistochemical staining}

The tissue chips used in this study for immunohistochemical staining were purchased from Shanghai Core Super Co., Ltd. The study was conducted in accordance with the Declaration of Helsinki (as revised in 2013). This study design was approved by the Human Research Ethics Committee of Shanghai Outdo Biotech Company (No.: YB M-05-01) and written informed consent had obtained from each patient before their original examination. The clinical characteristics of 150 patients in the tissue chips, such as age, pathological type, pathological grade, tumor invasion, lymph node metastasis, distant metastasis, mitosis, routine immunohistochemistry and survival status, were obtained from medical records (Table 1).

Immunohistochemical staining was used to detect the expression of LRP6 in breast cancer samples from tissue chips and the mouse tumor tissue. Two experienced pathologists who were blinded to the clinical information of the patients independently evaluated and recorded the immunohistochemical results. The intensity and degree of staining were evaluated in the cytomembrane. LRP6 expression was graded as 0 point (blue), 1 point (yellow), 2 points (brown), and 3 points (brown black), based on tumor cytomembrane staining intensity; grades were assigned based on the percentage of cells that were positive for LRP6 expression as follows: 0 point, $0-5 \%$; 1 point, $6-25 \%$; 2 points, $26-50 \%$; 3 points, $51-75 \%$; 4 points, $76-100 \%$. The scores obtained by optical density and positive percentage analysis (with $0-3$ and 4-7 points considered equal to weak and strong expression, respectively) were 
Table 1 Correlations between the LRP6 expression levels and the clinicopathological features of patients with breast cancer

\begin{tabular}{|c|c|c|c|c|}
\hline \multirow{2}{*}{ Variables } & \multirow{2}{*}{ Cases } & \multicolumn{2}{|c|}{ LRP6 } & \multirow{2}{*}{$P$ value } \\
\hline & & Low & High & \\
\hline Age group & & & & 0.666 \\
\hline$\leq 50$ years & 39 & 17 & 22 & \\
\hline$>50$ years & 111 & 44 & 67 & \\
\hline Grade & & & & 0.962 \\
\hline Poorly differentiated & 3 & 1 & 2 & \\
\hline Moderately differentiated & 122 & 50 & 72 & \\
\hline Well differentiated & 25 & 10 & 15 & \\
\hline Tumor stage & & & & 0.057 \\
\hline $\mathrm{T} 1$ & 41 & 23 & 18 & \\
\hline $\mathrm{T} 2$ & 91 & 31 & 60 & \\
\hline T3 & 18 & 7 & 11 & \\
\hline Regional lymph node stage & & & & 0.964 \\
\hline No & 79 & 31 & 48 & \\
\hline N1 & 38 & 16 & 22 & \\
\hline N2 & 20 & 9 & 11 & \\
\hline N3 & 13 & 5 & 8 & \\
\hline TNM stage & & & & 0.388 \\
\hline Stage I & 27 & 14 & 13 & \\
\hline Stage II & 84 & 31 & 53 & \\
\hline Stage III & 39 & 16 & 23 & \\
\hline Aurora-A & & & & $<0.001$ \\
\hline Negative & 12 & 11 & 1 & \\
\hline Positive & 138 & 50 & 88 & \\
\hline Aurora-B & & & & $<0.001$ \\
\hline Negative & 86 & 46 & 40 & \\
\hline Positive & 64 & 15 & 49 & \\
\hline FAK & & & & $<0.001$ \\
\hline Negative & 32 & 25 & 7 & \\
\hline Positive & 118 & 36 & 82 & \\
\hline Cofilin & & & & $<0.001$ \\
\hline Low & 59 & 38 & 21 & \\
\hline High & 91 & 23 & 68 & \\
\hline
\end{tabular}

Table 1 (continued)
Table 1 (continued)

\begin{tabular}{|c|c|c|c|c|}
\hline \multirow{2}{*}{ Variables } & \multirow{2}{*}{ Cases } & \multicolumn{2}{|c|}{ LRP6 } & \multirow{2}{*}{$P$ value } \\
\hline & & Low & High & \\
\hline ER & & & & 0.686 \\
\hline Negative & 61 & 26 & 35 & \\
\hline Positive & 89 & 35 & 54 & \\
\hline PR & & & & 0.495 \\
\hline Negative & 91 & 35 & 56 & \\
\hline Positive & 59 & 26 & 33 & \\
\hline HER-2 & & & & 0.002 \\
\hline Negative & 110 & 53 & 57 & \\
\hline Positive & 40 & 8 & 32 & \\
\hline Ki-67 & & & & 0.011 \\
\hline Negative & 95 & 46 & 49 & \\
\hline Positive & 55 & 15 & 40 & \\
\hline Molecular subtype & & & & 0.003 \\
\hline Luminal A & 55 & 29 & 26 & \\
\hline Luminal B & 35 & 7 & 28 & \\
\hline Triple negative & 24 & 6 & 18 & \\
\hline HER-2 overexpression & 36 & 19 & 17 & \\
\hline CK5/6 & & & & 0.751 \\
\hline Negative & 103 & 41 & 62 & \\
\hline Positive & 47 & 20 & 27 & \\
\hline$A R$ & & & & 0.061 \\
\hline Negative & 35 & 19 & 16 & \\
\hline Positive & 115 & 42 & 73 & \\
\hline P53 & & & & 0.122 \\
\hline Negative & 11 & 7 & 4 & \\
\hline Positive & 139 & 54 & 85 & \\
\hline EGFR & & & & 0.217 \\
\hline Negative & 97 & 43 & 54 & \\
\hline Positive & 53 & 18 & 35 & \\
\hline Src & & & & 0.018 \\
\hline Negative & 70 & 36 & 34 & \\
\hline Positive & 53 & 16 & 37 & \\
\hline
\end{tabular}

LRP6, lipoprotein receptor-related protein 6; FAK, focal adhesion kinase; ER, estrogen receptor; PR, progesterone receptor; HER2, human epidermal growth factor receptor-2; $A R$, androgen receptor; EGFR, epidermal growth factor receptor. 
used to classify LRP6 expression as positive (high staining intensity, $>5 \%$ ), or negative (low staining intensity, $<5 \%$ ) (9). ScanScope chip scanners (Aperio, vista, CA, USA) were used to scan the chips, and Image Scope software (Aperio, vista, CA, USA) was used to collect images of the representative areas. Adobe Illustrator (Adobe) was used for image analysis.

\section{siRNA transfection and construction of lentivirus transfected shRNA-LRP6 low expression cell line}

The process of siRNA transfection was as follows. Twentyfour hours before transfection, MCF-7 cells $\left(5 \times 10^{5}\right.$ cells/hole $)$ were inoculated into a 6-well plate containing $1 \mathrm{~mL}$ OptiMEM (GIBCO, Carlsbad, CA, USA), Subsequently, diluted si-LRP6 and LiPo3000 (Invitrogen, Carlsbad, CA, USA) were mixed with 1:1; further detection was performed after $48 \mathrm{~h}$ of culture.

Lentiviral shRNA-LRP6 was purchased from Gemma (Shanghai, China). MCF-7 cells $\left(2-3 \times 10^{5}\right.$ cells/well) were seeded on a 6-well plate and cultured for $24 \mathrm{~h}$. The viral solution and Polybrene at a final concentration of $5 \mu \mathrm{g} / \mathrm{mL}$ were added into the fresh medium \{virus dosage: [number of cells $\times$ MOI (multiplicity of infection) value/virus titer $\times 10^{3}=$ virus dosage $[\mu \mathrm{L}]\}$. After $12 \mathrm{~h}$, replace the fresh medium.

\section{Colony formation assay}

The expression of LRP6 was knocked down by an si-RNA technique in a group of MCF-7 cells obtained from the Chinese Academy of Sciences (ATCC, Beijing, China) (experimental group), while an untreated group of the same series of MCF-7 cells was used as control group. Cells in the logarithmic growth phase were digested with trypsin and seeded on in a petri dish at a density of 500 cells/dish. The petri dish was shaken gently so that the cells were evenly spread; the cells were then grown under standard cell culture conditions at $37^{\circ} \mathrm{C}$ in a humidified atmosphere with $5 \% \mathrm{CO}_{2}$ using DMEM-H medium (Gibco, Garlsbad, CA, USA) and $10 \%$ fetal bovine serum. After 15 days of culture, the cell culture medium was removed, and cells were fixed with pure methanol for 15 minutes, then stained with $5 \%$ crystal violet for 20 minutes, after which the number of colonies was counted.

\section{Transwell cell migration assay and cell invasion assay}

For the cell migration assay, cells in the logarithmic growth phase were digested with trypsin and diluted to a density of $1 \times 10^{5}$ cells $/ \mathrm{mL}$. An aliquot of $500 \mu \mathrm{L}$ medium containing $20 \%$ fetal bovine serum was added to the lower chamber of a Transwell (Corning Inc., Corning, NY, USA), and a $20 \mu \mathrm{L}$ aliquot of cell suspension was added to the upper chamber. After 24 hours of culture, 4\% paraformaldehyde was used as a fixative for 15 minutes, and the Transwell chamber was stained with $5 \%$ crystal violet for $10 \mathrm{~min}$, while the inoculation side of the upper chamber was wiped clean from any remaining cells with cotton swabs. The lower chamber was then photographed under a microscope to observe cell migration. There should have been no fewer than 10 parallel holes in each experimental group. Cells in each visual field were counted and the average value was taken for the final statistical evaluations.

For the cell invasion assays, Matrigel glue was diluted with serum-free medium before cell inoculation. The cells suspension was then slowly added to the Transwell upper chamber containing Matrigel and culture medium and cultured for 2 hours. The following steps of the procedure were the same as those used for the cell migration assays described above.

\section{Wound bealing assay}

Cells in the logarithmic growth phase were digested with trypsin and inoculated in a pre-labeled 6-well plate. After 24 hours of culture, cells formed an $80 \%$ confluent monolayer and were scratched with a $10 \mu \mathrm{L}$ sterile pipette tip. A culture medium containing $2 \%$ fetal bovine serum was used instead of the original medium (to reduce cell proliferation), and photographs were taken at 0,12 and $24 \mathrm{~h}$.

\section{Tumor model}

The nude mice experiments were performed under a project license (No. 2020278) granted by Laboratory Animal Management and Use Committee of Wuhan Seville Biotechnology Co., Ltd., in compliance with guidelines of Hubei province for the care and use of animals. Four-weekold female nude mice purchased from Seville Company (Hubei Province, China) were randomly divided into the lentivirus transfected sh-LRP6 group (experimental group) and sh-NC control group (n=7). Sh-LRP6-MCF-7 and shNC-MCF-7 cells were suspended in PBS and mixed with Matrigel in a ratio of $1: 1$. Estradiol cypionate $(2 \mathrm{mg} / \mathrm{kg}$ in corn oil, Med Chem Express, Shanghai, China, Cat: HYB1100) was subcutaneously injected in the chest at the level 
of the second pair of mammary fat pads on the right side with $1 \times 10^{6}$ cells. When a visible tumor was formed in the mice, the tumor size was measured once every 3 days, and the tumor volume was calculated according to the formula: volume $=\left(\right.$ length $\times$ width $\left.^{2}\right) / 2$. The mice were sacrificed 30 days after subcutaneous injection. All the transplanted tumors were removed from the mice and weighed immediately; the expression level of LRP6 in the tumors was then detected by immunohistochemistry. We have previously established the human breast cancer sh-LRP6MCF-7 (experimental group) and sh-NC-MCF-7 (control group) cell transplantation tumor models in nude mice. Data were collected and analyzed with GraphPad software (GraphPad Software, San Diego, CA, USA) to calculate tumor growth curves.

\section{Statistical analysis}

Chi-square test was used to analyze the relationship between LRP6 expression and clinicopathological features of breast cancer. Kaplan-Meier method and logarithmic rank sum test were used for survival analysis in 150 patients with breast cancer, luminal A type breast cancer, luminal B type breast cancer, HER-2 overexpression or triplenegative breast cancer. Cox proportional hazard regression model was used to analyze the potential prognostic factors. All statistical tests were two-tailed tests, where a $\mathrm{P}<0.05$ was considered statistically significant. SPSS Statistics 25.0 software (IBM SPSS, Armonk, NY, USA) was used for all calculations.

\section{Results}

Clinicopathological characteristics of patients with breast cancer

The detailed clinicopathological features of the patients with breast cancer included in this study are shown in Table 1 . Of the 150 patients, 111 were over 50 years old. The tumor size and invasion stage ( $T$ stage) included T1 stage $(n=41)$, T2 stage ( $\mathrm{n}=91)$, and T3 stage $(\mathrm{n}=18)$; the regional lymph node metastasis stage ( $\mathrm{N}$ stage) included N0 stage $(\mathrm{n}=79)$, N1 stage ( $n=38)$, N2 stage $(n=20)$, and N3 stage $(n=13)$; the TNM stage included stage I $(n=27)$, stage II $(n=84)$, and stage III $(n=39)$. Among the molecular subtypes of breast cancer, there were 55 cases of luminal A type, 35 cases of luminal B type, 24 cases of triple-negative breast cancer and 36 cases of HER-2 overexpression. Analysis of routine immunohistochemical indexes revealed that 110 cases were negative for HER-2 and 40 cases were positive; 61 cases were negative for estrogen receptor (ER) and 89 cases were positive; 91 cases were negative for progesterone receptor $(\mathrm{PR})$ and 59 cases were positive. Among the 150 breast cancer tissues by immunohistochemistry staining in tissue microarray (Figure 1A), 61 cases showed low expression of LRP6 (Figure 1B) and 89 cases showed high expression of LRP6 (Figure 1C).

\section{Relationship between LRP6 expression and clinicopatbological features of breast cancer}

We used the Chi-square test to study the relationship between the expression levels of LRP6 in breast cancer and the clinicopathological features of breast cancer (Table 1). A high expression of LRP6 was significantly related to HER-2 status, Aurora-A, Aurora-B, FAK, Src and Ki67 $(\mathrm{P}<0.05$, Table 1). Among the 110 HER-2 negative patients, 57 patients showed high expression of LRP6, with a proportion of patients displaying high expression of LRP6 equal to $51.82 \%$. Among the 40 HER-2-positive patients, 32 showed high expression of LRP6, with a proportion of patients displaying high expression of LRP6 equal to $80 \%$. The difference between the HER-2 positive and HER2 negative groups in the percentage of subjects with high LRP6 expression was statistically significant $(\mathrm{P}=0.002$, Table 1). Therefore, the proportion of subjects with high expression of LRP6 among HER-2-positive patients was higher than that in HER-2-negative patients. However, there was no significant correlation between LRP6 expression and tumor size staging, lymph node staging, mitosis, or ER and PR expression ( $\mathrm{P}>0.05$, Table 1$)$.

\section{Relationship between LRP6 expression and poor prognosis of breast cancer}

The overall survival rate of 150 patients with breast cancer was analyzed by Kaplan-Meier method and log-rank test. The overall survival rate of tumor patients with high expression of LRP6 was significantly lower than that of patients with low expression of LRP6 $(\mathrm{P}=0.002$, Figure $2 A)$. When stratifying the analysis by the different molecular types of breast cancer, There was no significant difference in overall survival between patients with high expression of LRP6 and those with low expression of LRP6 in patients with breast cancer of luminal A type $(\mathrm{P}>0.05$, Figure $2 B)$; among luminal $B$ type breast cancer patients, the survival 

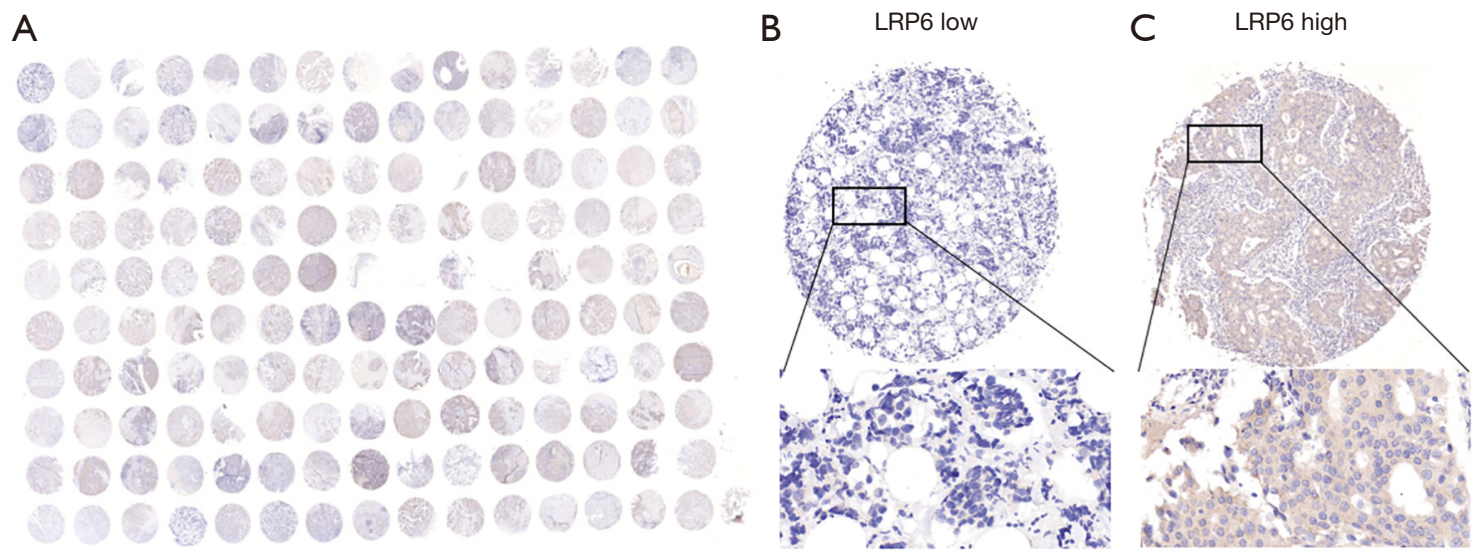

Figure 1 Tissue microarray and immunohistochemistry staining of LRP6 in breast cancer tissues. (A) Immunohistochemistry staining of LRP6 in breast cancer tissues microarray (150 cases of breast cancer tissue; $1 \times$ magnification). (B) Weakly positive expression of LRP6 in breast cancer tissues; 200× magnification. (C) Strongly positive expression of LRP6 in breast cancer tissues; 200× magnification.

rate of patients with high expression of LRP6 was significantly lower than that of patients with low expression of LRP6 ( $\mathrm{P}=0.034$, Figure 2C). There was no significant difference in overall survival between patients with high expression of LRP6 and those with low expression of LRP6 in patients with breast cancer of HER-2 overexpression or triple-negative breast cancer $(\mathrm{P}>0.05$, Figure $2 D, 2 E)$. We used univariate and multivariate Cox risk regression models to assess each risk factor for overall survival (Table 2). Univariate regression analysis showed that positive expression of Aurora-A (HR $=2.050,95 \%$ CI: 1.054-3.987, $\mathrm{P}=0.035)$, high expression of LRP6 (HR $=1.647$, 95\% CI: 1.108-2.448, $\mathrm{P}=0.014$ ), and high expression of Cofilin ( $\mathrm{HR}=1.510,95 \%$ CI: $1.017-2.240, \mathrm{P}=0.041$ ) were negative prognostic factors for breast cancer. In multivariate regression analysis, LRP6 was an independent risk factor for breast cancer, and the risk of death in the LRP6 high expression group was 1.653 times higher than that in the low expression group (95\% CI: 1.039-2.631, $\mathrm{P}=0.034)$.

\section{Effect of si-RNA knockdown of LRP6 on breast cancer cells cell clone formation}

We used RT-qPCR to detect the expression of LRP6 in MCF-7 and MCF-10A cell lines. The results showed that the expression of LRP6 in breast cancer cells was significantly higher than that in breast epithelial cells (Figure $3 A$ ). We used siRNA to knockdown the expression of LRP6 in MCF-7 cell lines (Figure 3B).
In order to further investigate the effect of LRP6 on the proliferation of breast cancer cells, we carried out a cell clone formation assay. In the MCF-7 cell line, LRP6 knockdown significantly reduced the cell clone formation rate as compared to that in the control group $(\mathrm{P}<0.05$, Figure 3C).

\section{Effects of si-RNA knockdown of LRP6 on breast cancer cell migration, invasion, and wound healing}

The results of Transwell assay showed that the migration and invasion of cells were significantly inhibited in the si-RNA knockdown LRP6 group as compared to that in the control group $(\mathrm{P}<0.05$, Figure $3 D)$. In the scratch experiment, the wound healing ability of the experimental group was significantly weaker than that of the control group $(\mathrm{P}<0.05$, Figure $3 E)$.

\section{Study on the relationship between LRP6 expression and transplanted tumors in nude mice}

We studied the effect of LRP6 on tumor formation in nude mice by constructing human breast cancer sh-LRP6MCF-7 (experimental group) and sh-NC-MCF-7 (control group) cell transplantation tumor models, we observed that the tumor growth rate of the experimental group was significantly lower than that of the control group; the size and weight of the 7 tumors that developed in nude mice in the experimental group were significantly smaller 
A

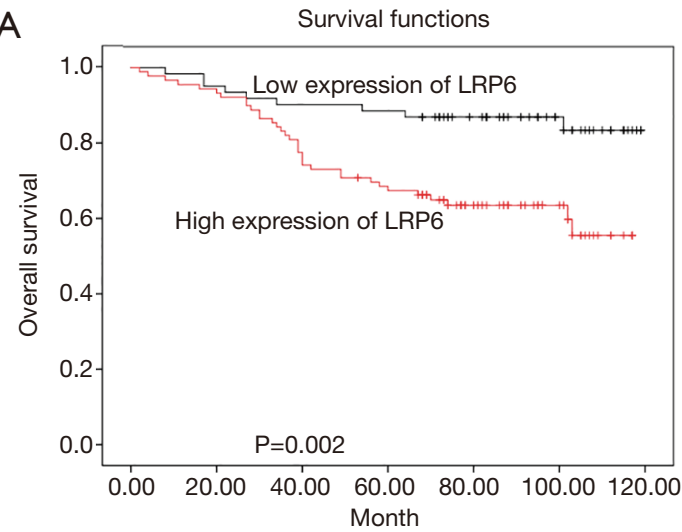

C

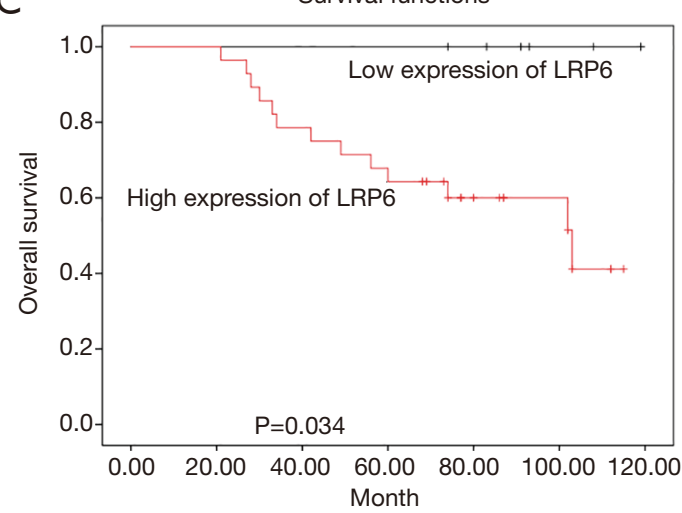

$E$

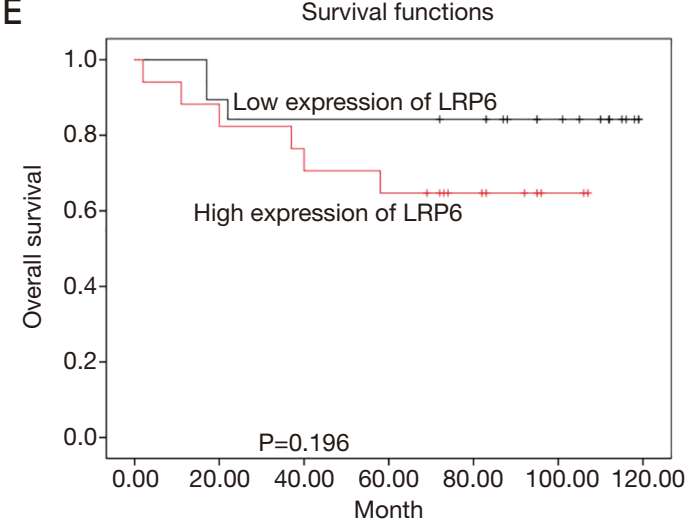

B

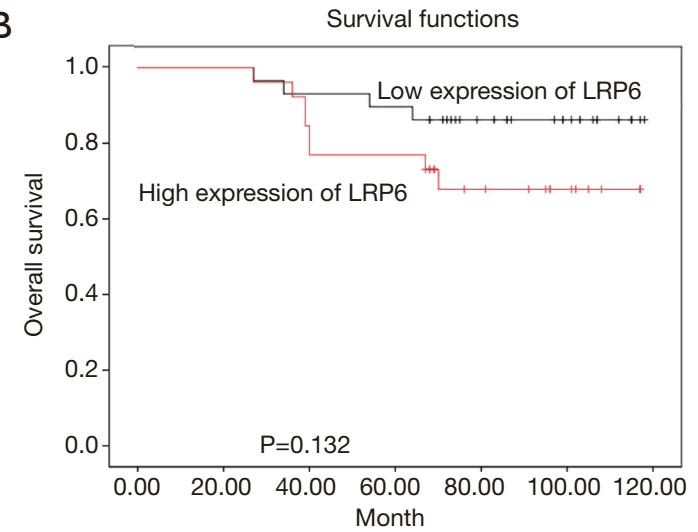

D

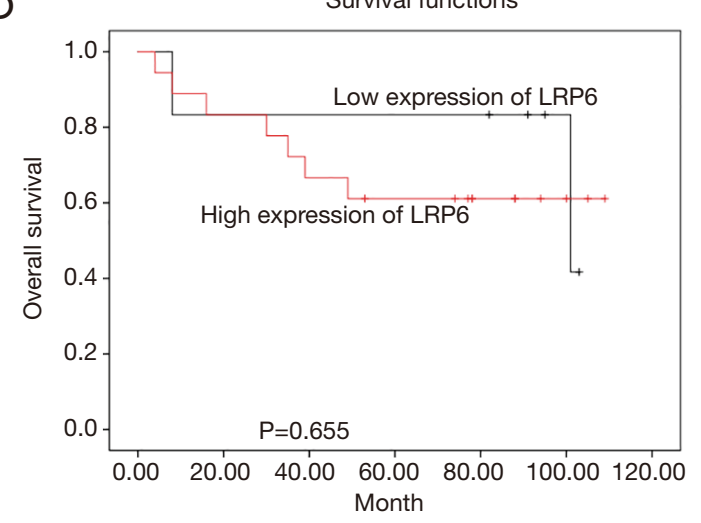

Figure 2 Kaplan-Meier curve analysis for the OS of all breast cancer patients and subtype breast cancer patients according to LRP6 expression. (A) Kaplan-Meier curve analysis for the OS of all breast cancer patients according to LRP6 expression. (B) Kaplan-Meier curve analysis for the OS of luminal A type breast cancer patients according to LRP6 expression. (C) KaplanMeier curve analysis for the OS of luminal B type breast cancer patients according to LRP6 expression. (D) Kaplan-Meier curve analysis for the OS of HER-2 overexpression breast cancer patients according to LRP6 expression. (E) Kaplan-Meier curve analysis for the OS of triple negative breast cancer patients according to LRP6 expression. LRP6, lipoprotein receptor-related protein 6; OS, overall survival. 
Table 2 Prognostic factors for OS in breast cancer by univariate and multivariate Cox regression analyses

\begin{tabular}{|c|c|c|c|c|}
\hline \multirow{2}{*}{ Variables } & \multicolumn{4}{|c|}{ OS } \\
\hline & HRs $(95 \% \mathrm{Cl})$ & $\mathrm{P}$ & HRs (95\% Cl) & $\mathrm{P}$ \\
\hline \multicolumn{5}{|l|}{ Age group } \\
\hline$\leq 50$ years & 1.0 [reference] & & 1.0 [reference] & \\
\hline \multicolumn{5}{|l|}{ Grade } \\
\hline Poorly differentiated & 1.0 [reference] & & 1.0 [reference] & \\
\hline Moderately differentiated & $0.253(0.033,1.917)$ & 0.184 & $0.251(0.032,1.991)$ & 0.191 \\
\hline Well differentiated & $0.298(0.038,2.338)$ & 0.249 & $0.252(0.031,2.085)$ & 0.201 \\
\hline T2 & $1.284(0.844,1.953)$ & 0.243 & $1.257(0.786,2.011)$ & 0.34 \\
\hline T3 & $2.374(1.070,5.267)$ & 0.033 & $3.131(1.308,7.496)$ & 0.011 \\
\hline \multicolumn{5}{|l|}{ Regional lymph node stage } \\
\hline No & 1.0 [reference] & & 1.0 [reference] & \\
\hline N1 & $0.877(0.555,1.385)$ & 0.573 & $0.792(0.488,1.286)$ & 0.346 \\
\hline $\mathrm{N} 2$ & $0.827(0.443,1.542)$ & 0.549 & $0.797(0.405,1.570)$ & 0.512 \\
\hline N3 & $0.846(0.363,1.972)$ & 0.699 & $0.629(0.231,1.713)$ & 0.365 \\
\hline \multicolumn{5}{|l|}{ Molecular subtype } \\
\hline Negative & 1.0 [reference] & & 1.0 [reference] & \\
\hline Positive & $2.050(1.054,3.987)$ & 0.035 & $1.892(0.855,4.187)$ & 0.115 \\
\hline \multicolumn{5}{|l|}{ Aurora-B } \\
\hline Negative & 1.0 [reference] & & & \\
\hline Positive & $1.233(0.830,1.833)$ & 0.299 & & \\
\hline \multicolumn{5}{|l|}{ LRP6 } \\
\hline Low & 1.0 [reference] & & 1.0 [reference] & \\
\hline High & $1.647(1.108,2.448)$ & 0.014 & $1.653(1.039,2.631)$ & 0.034 \\
\hline \multicolumn{5}{|l|}{ FAK } \\
\hline Negative & 1.0 [reference] & & 1.0 [reference] & \\
\hline Positive & $1.132(0.729,1.758)$ & 0.58 & $0.672(0.400,1.128)$ & 0.132 \\
\hline
\end{tabular}

Table 2 (continued) 
Table 2 (continued)

\begin{tabular}{|c|c|c|c|c|}
\hline \multirow{2}{*}{ Variables } & \multicolumn{4}{|c|}{ OS } \\
\hline & HRs $(95 \% \mathrm{Cl})$ & $P$ & HRs $(95 \% \mathrm{Cl})$ & $P$ \\
\hline \multicolumn{5}{|l|}{ Cofilin } \\
\hline Low & 1.0 [reference] & & 1.0 [reference] & \\
\hline \multicolumn{5}{|l|}{ ER } \\
\hline Negative & 1.0 [reference] & & & \\
\hline Positive & $0.996(0.676,1.468)$ & 0.985 & & \\
\hline \multicolumn{5}{|l|}{ PR } \\
\hline \multicolumn{5}{|l|}{ HER-2 } \\
\hline Negative & 1.0 [reference] & & & \\
\hline Positive & $1.073(0.730,1.577)$ & 0.718 & & \\
\hline \multicolumn{5}{|l|}{ Ki-67 } \\
\hline Negative & 1.0 [reference] & & & \\
\hline Positive & $1.145(0.768,1.706)$ & 0.506 & & \\
\hline \multicolumn{5}{|l|}{$\mathrm{CK} 5 / 6$} \\
\hline Negative & 1.0 [reference] & & & \\
\hline \multicolumn{5}{|l|}{ AR } \\
\hline Negative & $1.0[$ reference] & & & \\
\hline Positive & $1.582(0.732,3.422)$ & 0.244 & & \\
\hline \multicolumn{5}{|l|}{ EGFR } \\
\hline Negative & 1.0 [reference] & & & \\
\hline Positive & $1.003(0.673,1.495)$ & 0.989 & & \\
\hline \multicolumn{5}{|l|}{ Src } \\
\hline Negative & 1.0 [reference] & & & \\
\hline Positive & $1.135(0.733,1.759)$ & 0.57 & & \\
\hline
\end{tabular}

OS, overall survival; LRP6, lipoprotein receptor-related protein 6; FAK, focal adhesion kinase; ER, estrogen receptor; PR, progesterone receptor; HER-2, human epidermal growth factor receptor-2; AR, androgen receptor; EGFR, epidermal growth factor receptor. 
A

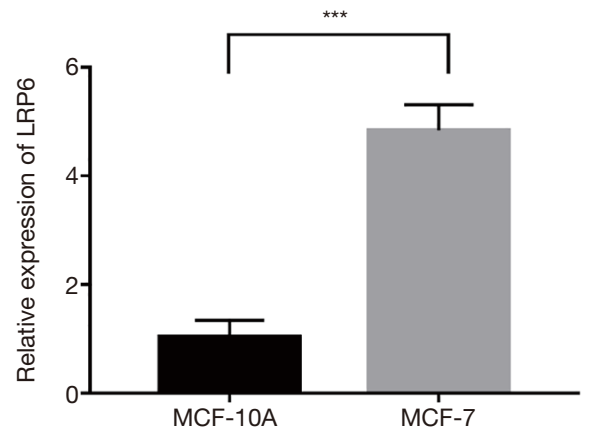

C

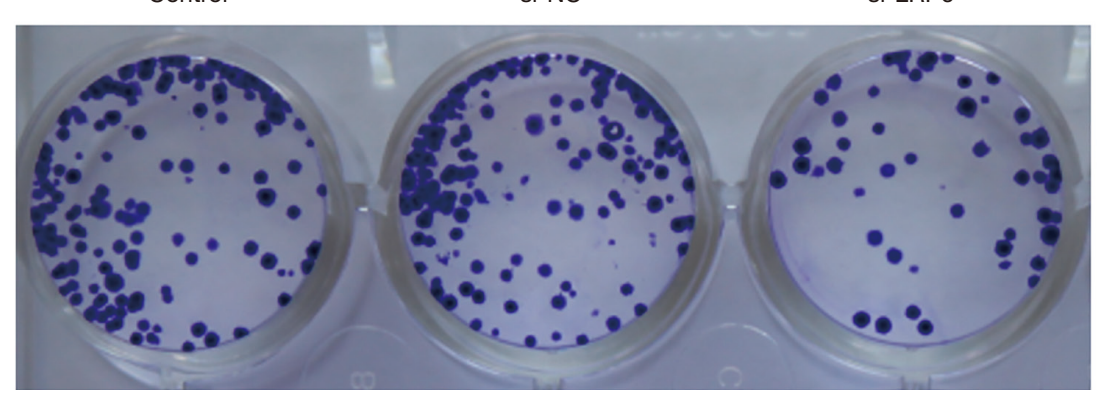

D
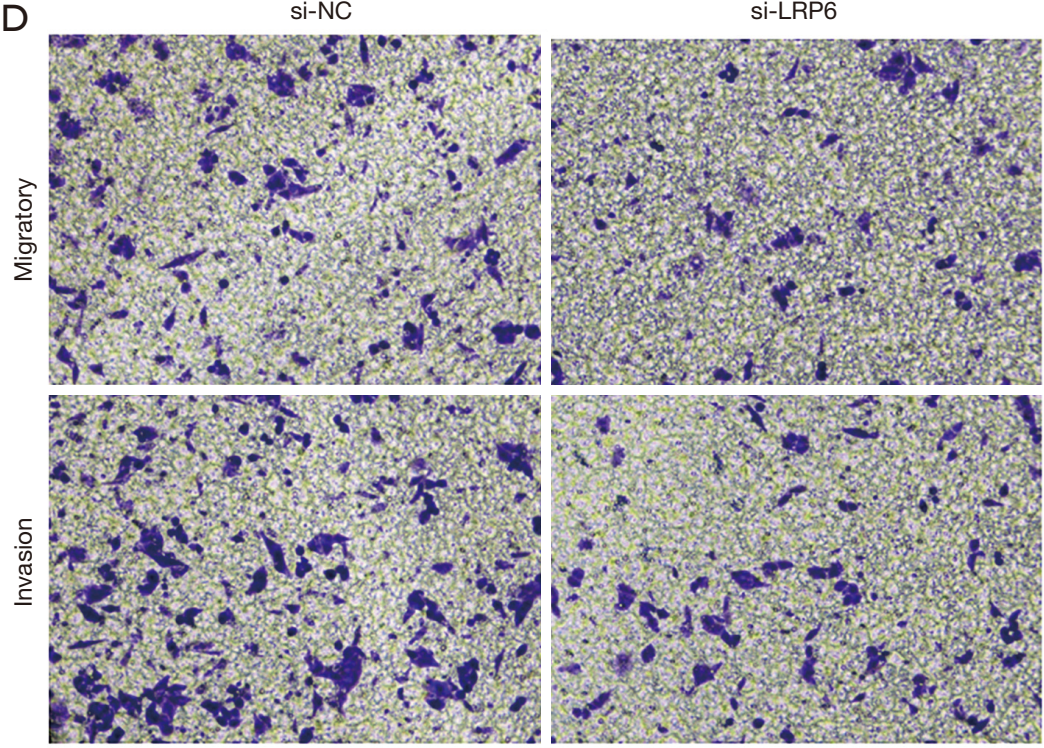

B
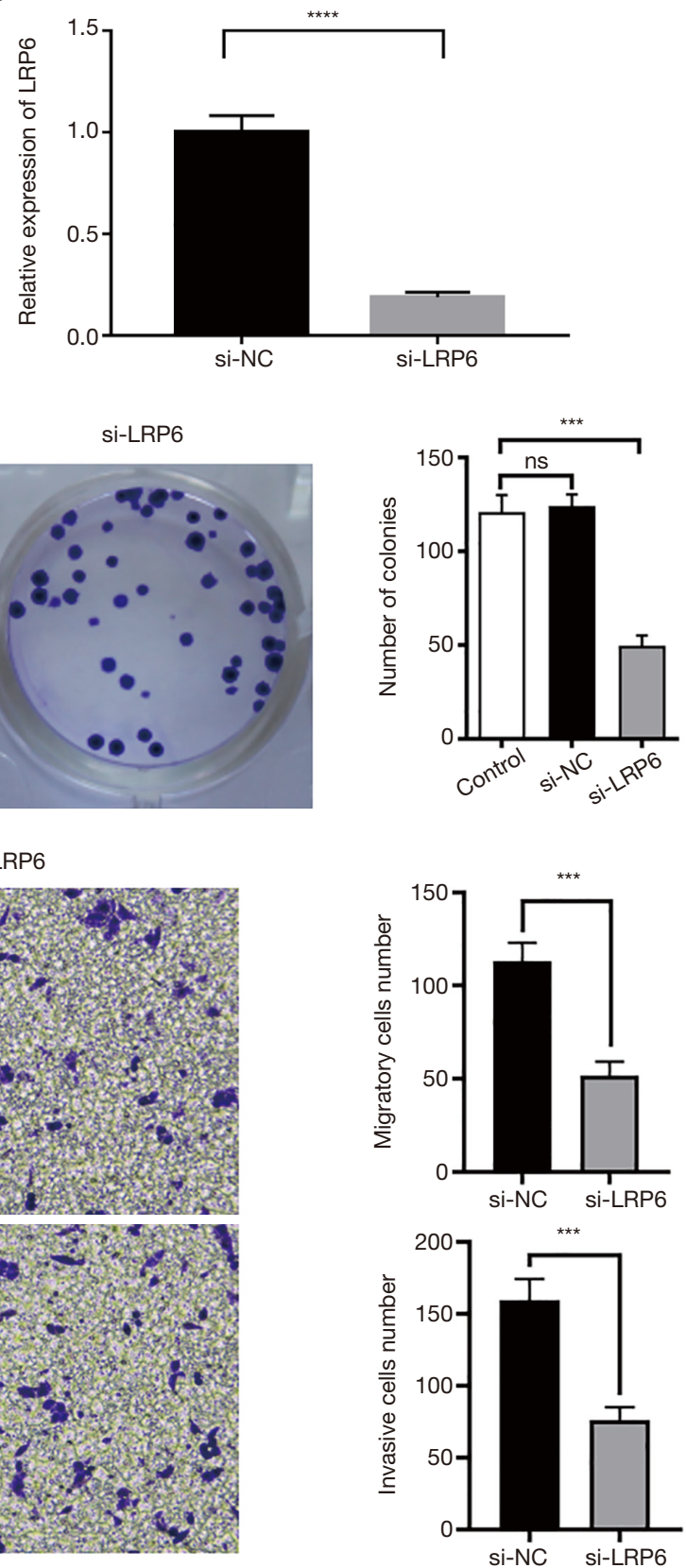

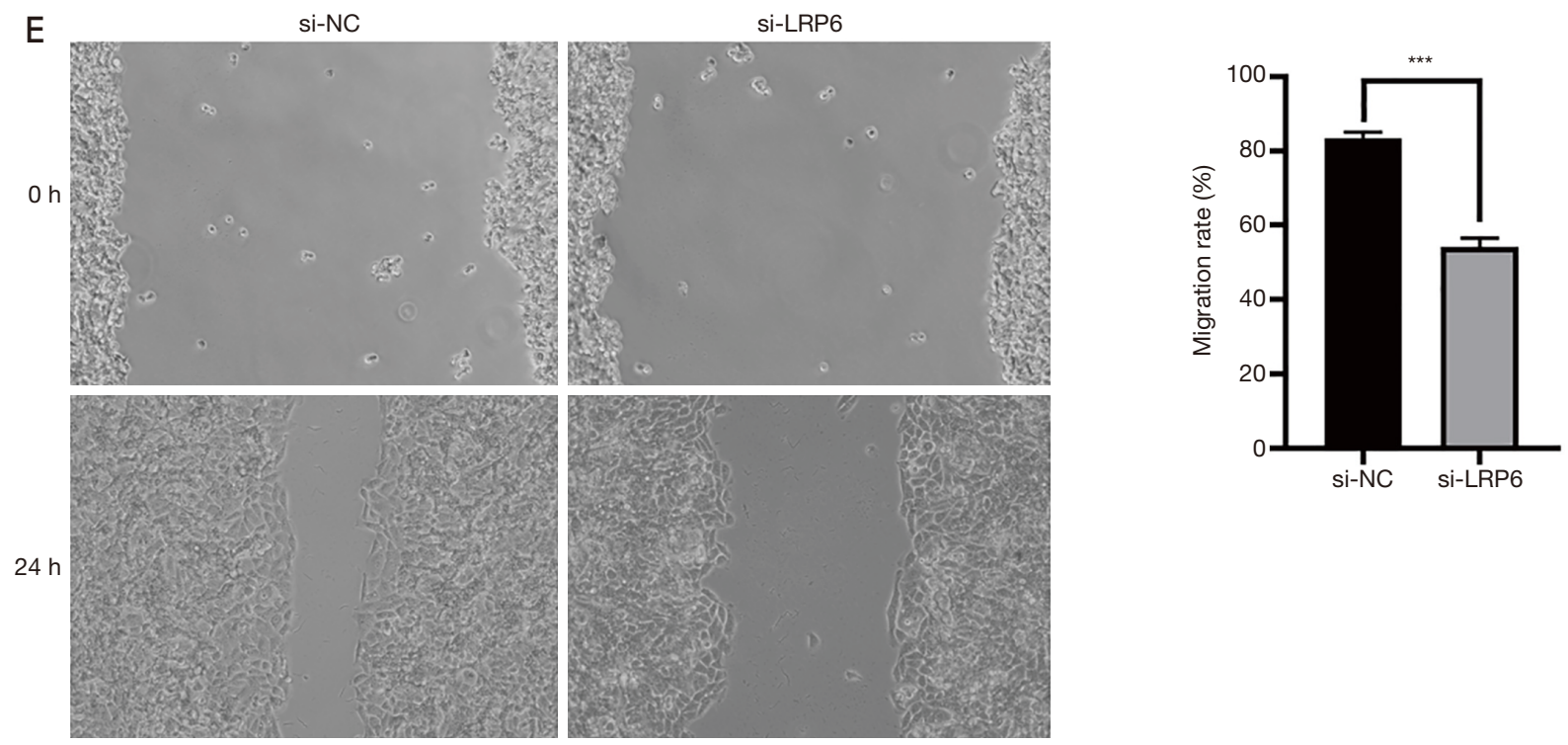

Figure 3 Effect of siRNA knockdown of LRP6 on the clonal formation, migration, invasion, and wound healing in MCF-7 cells. (A) Relative expression of LRP6 in MCF-10A and MCF7 cell lines; ${ }^{* * *} \mathrm{P}<0.001$. (B) Relative expression of LRP6 in si-NC and si-LRP6 group in MCF7 cell line; ${ }^{* * *} \mathrm{P}<0.00001$. (C) Effect of LRP6 expression on the clonal formation of breast cancer cells (staining method: $5 \%$ crystal violet); ${ }^{* * *} \mathrm{P}<0.001$. (D) Effect of LRP6 expression on cell migration and invasion (staining method: $5 \%$ crystal violet); ${ }^{* *} \mathrm{P}<0.001$ (100x magnification, scale bar: $100 \mathrm{um}$ ). (E) Effect of LRP6 expression on the wound healing of breast cancer cells; ${ }^{* *} \mathrm{P}<0.001$ (100× magnification, scale bar: $100 \mathrm{um}$ ).

than those of the control group. There was a significant difference in tumor growth volume and weight between the two groups $(\mathrm{P}<0.05$, Figure $4 A)$. We also used the immunohistochemistry staining to detect the expression of LRP6 in the transplanted tumors of the experimental group and the control group (Figure 4B).

\section{Discussion}

In recent years, individualized diagnosis and treatment and molecular targeted therapy for breast cancer patients have become topics of intense research. How to improve the overall survival rate and long-term prognosis of breast cancer patients has increasingly become the focus of clinicians. The most common subtype of breast cancer is ER positive luminal subtype, which accounts for $80 \%$ of cases of breast cancer. Current treatment for luminal subtype includes surgical removal, chemotherapy, radiotherapy and endocrine therapy. Despite the promising initial response to treatment, the recurrence, metastasis, and drug resistance of tumor are still the main causes of death among these patients (10). Therefore, there is an urgent need to develop new therapeutic targets for these patients.

The immunohistochemical staining performed in this study showed that in the tissue microarray of 150 cases of breast cancer, the proportion of patients with a high expression level of LRP6 was $59.3 \%$. Previous studies have found that the percentage of patients showing high expression levels of LRP6 in colorectal cancer, hepatocellular carcinoma and breast cancer are similar to that found in our study (8).

In this study, we found that age, tumor size stage, lymph node stage and mitosis were not significantly correlated with the expression of LRP6, suggesting that the expression of LRP6 is not influenced by these pathological factors in promoting the occurrence and development of breast cancer. Through univariate and multivariate regression analyses, we found that the high expression of LRP6 was an independent risk factor for breast cancer, and that it was positively correlated with mortality and poor prognosis of breast cancer. In agreement with what we observed in this study, previous studies revealed that high expression of LRP6 is associated with a malignant phenotype, metastatic potential, and poor prognosis also for epithelial tumors, such as hepatocellular carcinoma, oral squamous cell carcinoma, and colorectal cancer (11-15). Previous studies found that the expression level of LRP6 in ER, PR, and HER-2 negative breast tumors is higher than that in 

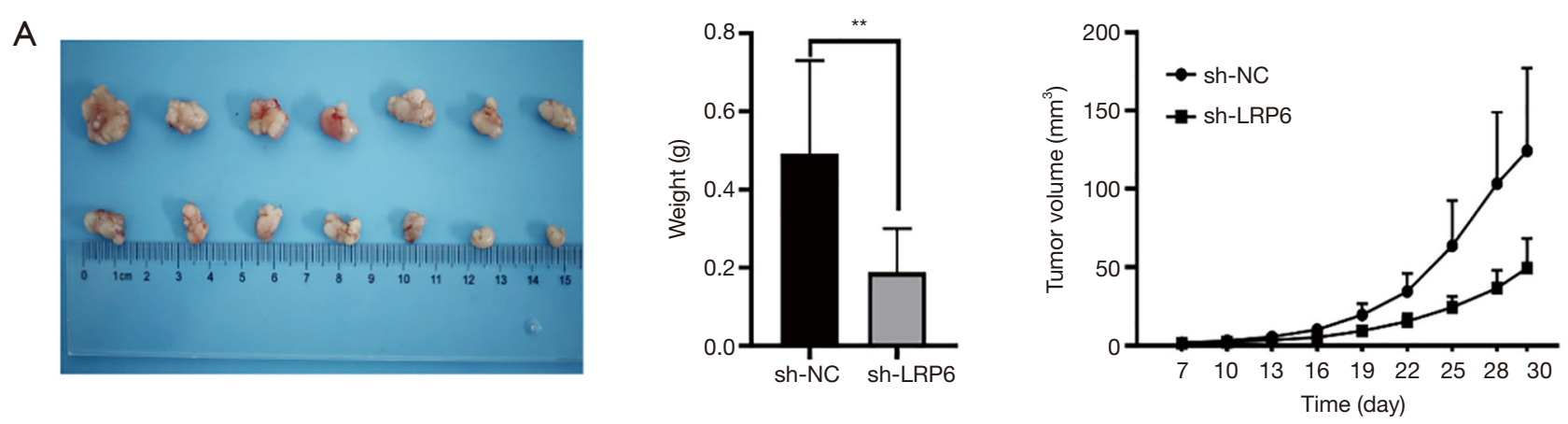

B

sh-NC

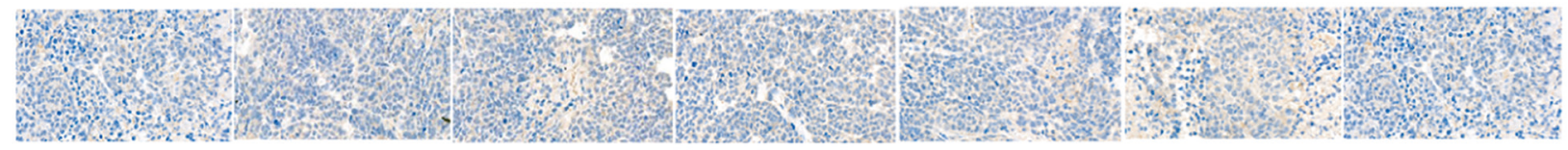

sh-LRP6

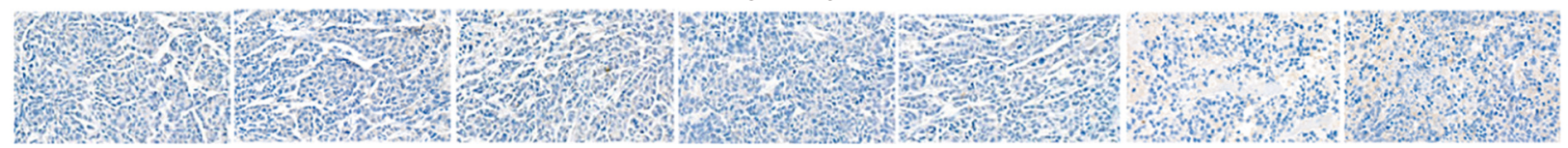

Figure 4 Growth of LRP6 knockdown cell lines in nude mice and immunohistochemistry staining of LRP6 in transplanted tumors. (A) Comparison of the growth, weight and volume of breast neoplasms between sh-NC group and sh-LRP6 group; ${ }^{* *} \mathrm{P}<0.01$. (B) Immunohistochemistry staining of LRP6 in breast cancer tissues in the two groups $(100 \times$ magnification, scale bar: $100 \mathrm{um})$. LRP6, lipoprotein receptor-related protein 6 .

ER, PR, and HER-2 positive breast tumors (16). In this study, we observed, no significant correlation between the expression of ER and PR and the expression of LRP6. The percentage of cases with high expression of LRP6 was higher among HER-2 positive than that among HER-2 negative patients, suggesting that LRP6 can still contribute to promotion, and development of breast cancer when ER, PR and HER-2 are positive.

Survival analysis showed that a high expression of LRP6 in breast cancer tissue was negatively correlated with the overall survival rate. When considering the molecular type of breast cancer, the expression of LRP6 in patients with luminal B type breast cancer was negatively correlated with the overall survival rate; however, in other molecular types, especially triple-negative breast cancer, there was no significant difference in overall survival rate between patients with high expression of LRP6 and those with low expression of LRP6. In our study, the results show that LRP6 may be an important factor affecting the occurrence and progression of breast cancer, and that the detection of LRP6 expression in breast cancer tissue samples is helpful for early diagnosis and prognosis. Similar conclusions were previously reported in the studies of colorectal cancer $(17,18)$.

The results of this study demonstrated that after knocking down LRP6, the clone formation rate, cell migration ability, invasion ability and wound healing ability of the breast cancer MCF-7 cell line was significantly lower than those of the control group. Similar experimental results were also found in bladder cancer cell line T24 (19). The results reported in the current literature suggest that the expression of LRP6 is up-regulated in human triplenegative breast cancer patients and human TNBC cell lines; conversely, the knockdown of LRP6 expression and treatment with recombinant MESD protein (a specific inhibitor of LRP6) significantly reduced the migration and invasion of TNBC MDA-MB-231 and BT549 cells (16). These previous results are similar to our results, but our study suggests that the high expression of LRP6 can still promote the proliferation, migration, and invasion of breast cancer cells when ER is positive. In our tumorigenic model in nude mice, inhibition of LRP6 expression led to inhibition of tumor growth, suggesting that LRP6 plays a key role in tumor proliferation. Ettenberg et al. reported that specific LRP6 antibodies or the LRP6 inhibitors 
MESD inhibit the growth of WNT1-or WNT3a-driven xenografts (20). These results suggest that LRP6 may be a new target for the treatment of breast cancer.

Previous studies have shown that natural compounds isolated from the plants, such as prodigiosin, silibinin, rottlerin, salinomycin and gigantol, inhibit the activity of $W n t / \beta$-catenin in TNBC cells by inhibiting the expression and phosphorylation of LRP6 (21-25). In addition, studies suggest that niclosamide induces LRP6 degradation in breast cancer cell lines, resulting in an increase in tumor cell apoptosis and a decrease in tumor cell proliferation (26).

\section{Conclusions}

Therefore, LRP6 can become a molecular targeting site for breast cancer therapy, and LRP6 inhibitors can be used in the treatment of breast cancer. Exploring the basic theory of the application of LRP6 inhibitors in breast cancer will be helpful towards the achievement of personalized targeted therapy for breast cancer patients.

\section{Acknowledgments}

We would like to thank Editage (www.editage.cn) for English language editing.

Funding: This work was supported by National Nature Science Foundation of China (grant number: 81702650).

\section{Footnote}

Reporting Checklist: The authors have completed the ARRIVE reporting checklist. Available at https://dx.doi. org/10.21037/gs-21-194

Data Sharing Statement: Available at https://dx.doi. org/10.21037/gs-21-194

Peer Review File: Available at https://dx.doi.org/10.21037/ gs-21-194

Conflicts of Interest: All authors have completed the ICMJE uniform disclosure form (available at https://dx.doi. org/10.21037/gs-21-194). All authors report that this work was supported by National Nature Science Foundation of China (grant number: 81702650).

Ethical Statement: The authors are accountable for all aspects of the work in ensuring that questions related to the accuracy or integrity of any part of the work are appropriately investigated and resolved. The study was conducted in accordance with the Declaration of Helsinki (as revised in 2013). The study was approved by ethics committee of Shanghai Outdo Biotech Company (No.: YB M-05-01) and informed consent was taken from all the patients. Experiments were performed under a project license (No.: 2020278) granted by Laboratory Animal Management and Use Committee of Wuhan Seville Biotechnology Co., Ltd., in compliance with guidelines of Hubei province for the care and use of animals.

Open Access Statement: This is an Open Access article distributed in accordance with the Creative Commons Attribution-NonCommercial-NoDerivs 4.0 International License (CC BY-NC-ND 4.0), which permits the noncommercial replication and distribution of the article with the strict proviso that no changes or edits are made and the original work is properly cited (including links to both the formal publication through the relevant DOI and the license). See: https://creativecommons.org/licenses/by-nc-nd/4.0/.

\section{References}

1. DeSantis CE, Ma J, Gaudet MM, et al. Breast cancer statistics, 2019. CA Cancer J Clin 2019;69:438-51.

2. Zhou T, Zhan J, Fang W, et al. Serum low-density lipoprotein and low-density lipoprotein expression level at diagnosis are favorable prognostic factors in patients with small-cell lung cancer (SCLC). BMC Cancer 2017;17:269.

3. Jiang L, Jiang S, Lin Y, et al. Combination of body mass index and oxidized low density lipoprotein receptor 1 in prognosis prediction of patients with squamous non-small cell lung cancer. Oncotarget 2015;6:22072-80.

4. Migita T, Ruiz S, Fornari A, et al. Fatty acid synthase: a metabolic enzyme and candidate oncogene in prostate cancer. J Natl Cancer Inst 2009;101:519-32.

5. Appert-Collin A, Bennasroune A, Jeannesson P, et al. Role of LRP-1 in cancer cell migration in 3-dimensional collagen matrix. Cell Adh Migr 2017;11:316-26.

6. Dedieu S, Langlois B, Devy J, et al. LRP-1 silencing prevents malignant cell invasion despite increased pericellular proteolytic activities. Mol Cell Biol 2008;28:2980-95.

7. Roslan Z, Muhamad M, Selvaratnam L, et al. The Roles of Low-Density Lipoprotein Receptor-Related Proteins 5, 6, and 8 in Cancer: A Review. J Oncol 2019;2019:4536302.

8. Raisch J, Côté-Biron A, Rivard N. A Role for the WNT 
Co-Receptor LRP6 in Pathogenesis and Therapy of Epithelial Cancers. Cancers (Basel) 2019;11:1162.

9. Maimaiti Y, Liu Z, Tan J, et al. Dephosphorylated cofilin expression is associated with poor prognosis in cases of human breast cancer: a tissue microarray analysis. Onco Targets Ther 2016;9:6461-6.

10. Kumar S, Srivastav RK, Wilkes DW, et al. Estrogendependent DLL1-mediated Notch signaling promotes luminal breast cancer. Oncogene 2019;38:2092-107.

11. González-Sancho JM, Aguilera O, García JM, et al. The Wnt antagonist DICKKOPF-1 gene is a downstream target of beta-catenin/TCF and is downregulated in human colon cancer. Oncogene 2005;24:1098-103.

12. Jia $\mathrm{Q}, \mathrm{Bu} \mathrm{Y}$, Wang $Z$, et al. Maintenance of stemness is associated with the interation of LRP6 and heparinbinding protein CCN2 autocrined by hepatocellular carcinoma. J Exp Clin Cancer Res 2017;36:117.

13. Liu Z, Sun B, Qi L, et al. Dickkopf-1 expression is downregulated during the colorectal adenoma-carcinoma sequence and correlates with reduced microvessel density and VEGF expression. Histopathology 2015;67:158-66.

14. Qi L, Sun B, Liu Z, et al. Dickkopf-1 inhibits epithelialmesenchymal transition of colon cancer cells and contributes to colon cancer suppression. Cancer Sci 2012;103:828-35.

15. Yuan $Y$, Xie X, Jiang $Y$, et al. LRP6 is identified as a potential prognostic marker for oral squamous cell carcinoma via MALDI-IMS. Cell Death Dis 2017;8:e3035.

16. Ma J, Lu W, Chen D, et al. Role of Wnt Co-Receptor LRP6 in Triple Negative Breast Cancer Cell Migration and Invasion. J Cell Biochem 2017;118:2968-76.

17. Lemieux E, Cagnol S, Beaudry K, et al. Oncogenic KRAS signalling promotes the $\mathrm{Wnt} / \beta$-catenin pathway through LRP6 in colorectal cancer. Oncogene 2015;34:4914-27.

Cite this article as: Zhang Y, Shu C, Maimaiti Y, Wang S, Lu C, Zhou J. LRP6 as a biomarker of poor prognosis of breast cancer. Gland Surg 2021;10(8):2414-2427. doi: 10.21037/gs-21194
18. Yao Q, An Y, Hou W, et al. LRP6 promotes invasion and metastasis of colorectal cancer through cytoskeleton dynamics. Oncotarget 2017;8:109632-45.

19. Jiang F, Qi W, Wang $Y$, et al. lncRNA PEG10 promotes cell survival, invasion and migration by sponging miR134 in human bladder cancer. Biomed Pharmacother 2019;114:108814.

20. Ettenberg SA, Charlat O, Daley MP, et al. Inhibition of tumorigenesis driven by different $\mathrm{Wnt}$ proteins requires blockade of distinct ligand-binding regions by LRP6 antibodies. Proc Natl Acad Sci U S A 2010;107:15473-8.

21. Lu W, Li Y. Salinomycin suppresses LRP6 expression and inhibits both $\mathrm{Wnt} / \beta$-catenin and mTORC1 signaling in breast and prostate cancer cells. J Cell Biochem 2014;115:1799-807.

22. Lu W, Lin C, King TD, et al. Silibinin inhibits Wnt/ $\beta$-catenin signaling by suppressing Wnt co-receptor LRP6 expression in human prostate and breast cancer cells. Cell Signal 2012;24:2291-6.

23. Lu W, Lin C, Li Y. Rottlerin induces Wnt co-receptor LRP6 degradation and suppresses both $\mathrm{Wnt} / \beta$-catenin and mTORC1 signaling in prostate and breast cancer cells. Cell Signal 2014;26:1303-9.

24. Wang Z, Li B, Zhou L, et al. Prodigiosin inhibits Wnt/ $\beta$-catenin signaling and exerts anticancer activity in breast cancer cells. Proc Natl Acad Sci U S A 2016;113:13150-5.

25. Yu S, Wang Z, Su Z, et al. Gigantol inhibits Wnt/ $/$-catenin signaling and exhibits anticancer activity in breast cancer cells. BMC Complement Altern Med 2018;18:59.

26. Lu W, Lin C, Roberts MJ, et al. Niclosamide suppresses cancer cell growth by inducing Wnt co-receptor LRP6 degradation and inhibiting the $\mathrm{Wnt} / \beta$-catenin pathway. PLoS One 2011;6:e29290. 